\title{
Emulsion and Suspension for Emulsion for Injection Dosage Form
}

National Cancer Institute

\section{Source}

National Cancer Institute. Emulsion and Suspension for Emulsion for Injection Dosage

Form. NCI Thesaurus. Code C149477.

Sterile emulsion and sterile suspension, both of which contain active substance(s),

intended for the preparation of an emulsion for injection by mixing the emulsion and the suspension. 